I N S T I T U T O

DE

M E D I C I N A

T R O P I C A L

$\mathrm{DE}$

SÃO PAULO

JOURNAL OF THE SÃO PAULO INSTITUTE OF TROPICAL MEDICINE

${ }^{1}$ Fundação Oswaldo Cruz, Instituto Oswaldo Cruz, Laboratório Interdisciplinar de Vigilância Entomológica em Diptera e Hemiptera, Rio de Janeiro, Rio de Janeiro, Brazil

${ }^{2}$ Fundação Oswaldo Cruz, Instituto Oswaldo Cruz, Laboratório de Diptera, Rio de Janeiro, Rio de Janeiro, Brazil

Correspondence to: Vanessa Rendeiro Vieira

Fundação Oswaldo Cruz, Instituto Oswaldo Cruz, Laboratório Interdisciplinar de Vigilância Entomológica em Diptera e Hemiptera, Avenida Brasil, 4365, Manguinhos, CEP 21040-900, Rio de Janeiro, RJ, Brazil

E-mail: nessarvieira@gmail.com

Received: 23 February 2021

Accepted: 13 July 2021

\section{Biodiversity assessment of Phlebotomine (Diptera: Psychodidae) in an environmental impacted area in Rio de Janeiro State, Brazil}

\author{
Vanessa Rendeiro Vieira ${ }^{1,2}$, Gustavo Marins de Aguiar ${ }^{2}$, Alfredo Carlos \\ Rodrigues de Azevedo', Elizabeth Ferreira Rangel ${ }^{\circledR}{ }^{1}$, Anthony Érico \\ Guimarães ${ }^{(1)}$
}

\section{ABSTRACT}

From October 1994 to September 1996, in the municipality of Mangaratiba, Rio de Janeiro State, phlebotomines were captured on the walls of the houses by means of a manual suction tube and light traps, in the household, the peridomicile and in the forest. As it is an area undergoing a real expansion and an increment in the local tourism, with the purpose of assessing changes in the phlebotomine fauna caused by environmental changes in the region, new captures were made in the same location from October 2015 to September 2016, this time using only light traps. In the two phases of the study, a total of 6,681 phlebotomines were captured. The results indicated that $\mathrm{Ny}$. intermedia and $\mathrm{Mg}$. migonei are fully adapted to this anthropic environment, while Pi. fischeri was more abundant and eclectic, and was probably attracted to exercise hematophagy. Nyssomyia intermedia can be suggested as the main vector of the etiological agent of the American Tegumentary Leishmaniasis in the studied areas. Pintomyia fischeri can also transmit Leishmania braziliensis, both in the environment altered by human action, and in the wild environment. Phlebotomines were captured in greater numbers between 6 and $8 \mathrm{pm}$ in the peridomicile and between 9 and $11 \mathrm{pm}$ in the household. The highest densities of phlebotomines were recorded in December, January and February. Despite almost 20 years between the two studies in the municipality of Mangaratiba, there was no change in the profile of the phlebotomine fauna in general; however, there was a greater density of species of medical importance in areas that suffered environmental impacts.

KEYWORDS: American Tegumentary Leishmaniasis. Sand flies. Fauna. Hourly frequency. Monthly frequency.

\section{INTRODUCTION}

In the last decades, the American Tegumentary Leishmaniasis (ATL) has been increasing in incidence and has geographically expanded revealing new eco-epidemiological scenarios in the American continent as a consequence of environmental impacts. In Brazil, this parasitosis has been installed in the periphery of large cities, in some State capitals, presenting with three epidemiological patterns: the wild pattern, where transmission occurs in an area of primary vegetation, being a zoonosis of wild animals, which can affect humans when they enter into contact with the environment, where the enzooty is occurring; the occupational and leisure pattern in which transmission is associated with the disordered exploitation of the forest and the clearing of the forests for the construction of roads, hydroelectric plants, villages, timber extraction, agriculture and ecotourism; and, finally, the 
pattern associated with rural and peri-urban areas of ancient colonization which is related to the migratory process, the occupation of slopes and agglomerates in urban centers associated with secondary forests. These patterns corroborate the complexity of the ATL transmission process, with different agents, reservoirs and vectors, and still have limited knowledge about some aspects, making the control this zoonosis very difficult ${ }^{1}$.

In the Southeast region of Brazil, the intense anthropic action has caused important changes in the behavior of vectors and reservoirs, with greater adaptation of these to human habitats. Such occurrences allowed the infection of domestic animals and, consequently, of women and children that, normally, do not frequent the Atlantic Forest residual forests. These aspects can be verified, in both, rural and urban ruralized areas, or even in the periphery of large urban centers ${ }^{1}$.

The changes in the environment caused by humans have contributed to the frank process of expansion and urbanization of ATL in Rio de Janeiro State, in areas of continuous population flow, especially those of intense tourism, such as the Costa Verde region ${ }^{2}$. Their existing traditional communities are characterized by subsistence agriculture, handmade fishing, in addition to some different economic activities, introduced in their daily lives after the opening of the Rio-Santos highway (BR 101), which facilitated the advance of tourism and real speculation in these places. Thus, the resulting occupations are forms of non-harmonic settlement and, due to their characteristics, in recent decades, they have led to the proliferation of areas at high risk of infection by Leishmania (V.) braziliensis ${ }^{3}$.

The ATL expansion process in Rio de Janeiro State requires the monitoring of the bioecology of phlebotomines that occurs in endemic areas, especially assessing the change in the vector behavior. The proposed study aims to provide information to assist in the planning and development of surveillance actions to reduce the risks of transmission of this parasitosis in the studied areas.

\section{MATERIALS AND METHODS}

\section{Study site}

The Costa Verde region is composed of three municipalities in Rio de Janeiro State: Mangaratiba, Angra dos Reis and Paraty; it has a significant part of occupied by Conservation Units, in addition to integrating the Serra do Mar Biodiversity Corridor, one of the richest areas in biodiversity across the Atlantic Forest ${ }^{4}$. The region, previously occupied by the Tupinamba people, was donated in 1568 as the first Sesmaria to the Sa family, thus initiating the colonization process in the municipality of Mangaratiba. It was only in 1920 that the municipality had a great urban growth, with tourism on the rise, houses being built for summer holidays and small villages transformed into seaside towns. After the inauguration of the Rio-Santos highway (BR 101), in the 1970s, there was a major demographic expansion in the municipality, resulting in a larger and real development of the area associated with the construction of condominiums, resorts and luxury hotels ${ }^{5}$.

In this study, systematic captures of phlebotomines were made, in an area of occurrence of human cases of ATL in the Costa Verde region, in the municipality of Mangaratiba, Rio de Janeiro State, located at coordinates $22^{\circ} 57^{\prime} 45^{\prime \prime} \mathrm{S}$. latitude and $44^{\circ} 02^{\prime} 04^{\prime \prime} \mathrm{W}$. Gr. longitude, $105 \mathrm{~km}$ away from the city of Rio de Janeiro via BR 101. This region has been suffering from constant environmental impacts, mainly due to tourism and real exploitation.

\section{Capture of sand flies}

Captures of phlebotomines were carried out initially, from October 1994 to September 1996, monthly, for two consecutive days, using manual aspirators, on the internal and external walls of the houses, from 6 to $8 \mathrm{pm}, 9$ to $11 \mathrm{pm}$, and 12 to 2 am by using light traps, Falcão model, modified by Aguiar $\mathrm{et} \mathrm{al} .{ }^{6}$, installed in the household, the peridomicile and the forest, 300 meters from the residence, from $6 \mathrm{pm}$ to 6 am of the next morning.

Captures were resumed in the same location in Mangaratiba, with the purpose of verifying possible changes in the profile of the phlebotomine fauna, from October 2015 to September 2016, monthly, for two consecutive nights, using this time using CDC light traps, $\mathrm{HP}$ model $^{7}$, installed in the household, the peridomicile and the forest, 300 meters from the residence, from $6 \mathrm{pm}$ to 8 am of the next morning.

The house, which served as a monitoring station (MS) for the capture of phlebotominesin both phases of the study, was chosen due to the registration of two autochthonous human cases of ATL (first phase) and also due to the favorable environment for carrying out the study, with presence of domestic animals and a relative proximity to the forest (about 300 meters).

\section{Process for the identification of sand flies}

The phlebotomines, captured by manual aspirators and with light traps, were placed at alow temperature $\left(-4{ }^{\circ} \mathrm{C}\right)$ for $10 \mathrm{~min}$ and then transferred to glasses containing $70 \%$ alcohol in which they were transported with the appropriate capture labels. A screening was carried out in the laboratory, separating phlebotomines from other insects, from the 
glasses containing specimens captured by the light traps. The specimens were assembled using a stereoscopic microscope, after processing these specimens adopting the Young and Perkins ${ }^{8}$ technique, modified by Aguiar et al. ${ }^{6}$, in which specimens are placed in petri dishes containing $10 \%$ potash for two hours to soften the chitin, then 20 minutes in the acetic acid to remove the excess of potash, five minutes in distilled water for washing the specimens and finally 24 hours in lactophenol for diaphanization. Next, the specific diagnosis was made under a bacteriological microscope by examining the morphological characteristics that should be clearly evident after diaphanization. For the specific identification of phebotomines, the designation of Galati ${ }^{9}$ was used. The specimens were deposited in the entomological collection of the Diptera Laboratory, sector of phlebotomines, Oswaldo Cruz Institute, FIOCRUZ.

\section{Data analysis}

To analyze the absolute abundance and the spatial distribution of phlebotomines, the Index of Species Abundance (ISA) and the Standardized Index of Species Abundance $(\text { SISA })^{10}$, whose purpose is to make a classification based on the absolute abundance and the spatial distribution of species in a given location. ISA was calculated using the Microsoft ${ }^{\circledast}$ Excel version 15.0 (Microsoft Corporation, Redmond, Washington D.C., USA) and the values were converted between zero and one (SISA). This analysis was performed only with the data from the second phase of the study, since the data from the first phase were grouped by month of collection and not by sample, and to calculate ISA and SISA it is important that samples are separated, because the abundance is analyzed according to the number of times the species was present on the day of capture.

The Pearson's Correlation Coefficient (r) was used to correlate the catch times of the main species on the internal and external walls of the households with a range of values from +1 to -1 , where 0 indicates that there is no association between the two variables, greater than 0 indicates a positive association, that is, as the value of one variable increases, so does the value of the other variable; less than 0 indicates a negative association, that is, as the value of a variable increases the other decreases. To observe the distribution of species in the two phases of the study, in the different points and places of capture, the analysis of absolute and relative frequency was used.

The seasonality of the species of sand flies was calculated using the Williams' averages, according to the definitions of Haddow ${ }^{11,12}$ and Forattini et al. ${ }^{13}$. All analyzes were performed with the Microsoft ${ }^{\circledR}$ Excel version 16.0 (Microsoft Corporation, Redmond, Washington D.C., USA).

\section{RESULTS}

Total overall of the first and second phases of the study

After adding all the locations and types of capture, in the two phases of the study, a total of 6,681 phlebotomines were obtained, as can be seen in Table 1. Eleven species, belonging to seven genera, were captured in the first period and nine species with five genera, in the second one. The species Nyssomyia intermedia (Lutz and Neiva 1912), Pintomyia fischeri (Pinto 1926), Migonemyia migonei (França 1920), Nyssomyia whitmani (Antunes and Coutinho 1939), Pintomyia bianchigalatiae (Andrade Filho, Aguiar, Dias and Falcão 1999), Pintomyia pessoai (Coutinho and Barretto 1940), Psathyromyia shannoni (Dyar 1929), Pintomyia monticola (Costa Lima 1932) and Psychodopygus ayrozai (Barretto and Coutinho 1940) were found in the two stages of this study, while Evandromyia edwardsi (Mangabeira 1941b) and Micropygomyia schreiberi (Martins, Falcão and Silva 1955) were only found in the first phase, with one specimen each. Still in Table 1, the largest number of specimens was captured in the 90's $(63.6 \%)$, with catches for two consecutive years, from October 1996 to September 1994, showing Ny. intermedia as the most prevalent species with $80.9 \%$, followed by Pi. fischeri with $12.2 \%, M g$. migonei $6.2 \%, \mathrm{Ny}$. whitmani, with a very small number of $0.3 \%$ and the remaining species corresponding to $0.4 \%$. In captures made after 20 years, from October 2015 to September 2016, Ny. intermedia prevailed as the predominant species, representing $62.1 \%$ of the total, followed by Pi. fischeri with $22.2 \%$ and

Table 1 - Total of phlebotomines captured from October 1994 to September 1996 and October 2015 to September 2016, in the Municipality of Mangaratiba, Rio de Janeiro State, Brazil.

\begin{tabular}{lcc}
\hline \multirow{2}{*}{ Species } & \multicolumn{2}{c}{ Total } \\
\cline { 2 - 3 } & $1994-1996$ & $2015-2016$ \\
\hline Nyssomyia intermedia & 3,433 & 1,513 \\
Pintomyia fischeri & 518 & 540 \\
Migonemyia migonei & 262 & 175 \\
Nyssomyia whitmani & 11 & 118 \\
Pintomyia bianchigalatiae & 2 & 46 \\
Pintomyia pessoai & 4 & 24 \\
Psathyromyia shannoni & 5 & 12 \\
Pintomyia monticola & 6 & 6 \\
Psychodopygus ayrozai & 3 & 1 \\
Evandromyia edwardsi & 1 & - \\
Micropygomyia schreiberi & 1 & - \\
\hline Total & 4,246 & 2,435 \\
\hline
\end{tabular}


Mg. migonei with 7.2\%; in this period there was an increase in the prevalence of $N y$. whitmani with $4.8 \%$ and the other species corresponding to $3.7 \%$.

Captures on internal and external walls in the first phase of study

In this study, 2,003 specimens of the three main species were captured perched on the walls, with a greater number on the external walls of the houses (78\%). Nyssomyia intermedia was the species that predominated among the species in the internal walls $(87.7 \%)$, and in the external walls $(87.2 \%)$, followed by Pi. fischeri $(10 \%)$ on the internal walls and $M g$. migonei (7.7\%) on the external walls. Regarding the sex, females of Pi. fischeri were captured in greater numbers, both on the internal and external walls, at a rate of $94.3 \%$. To a lesser extent, the same occurred with $N y$. intermedia, showing $61.7 \%$ of females, however, in relation to $\mathrm{Mg}$. migonei the opposite happened, with a higher number of males, $64.1 \%$ (Figure 1).

\section{Hourly frequency of the main species of the first phase of study}

Regarding the hourly frequency, it was noted that the majority of phlebotomines, captured resting on the inner walls, were obtained between $9 \mathrm{pm}$ to $2 \mathrm{am}$, with a maximum peak between 9 to $11 \mathrm{pm}$ for $N y$. intermedia, in the proportion of $63.7 \%$ and Pi. fischeri between 12 to 2 am, with $70.5 \%$. The reverse occurred on the external walls of the studied households, with the longest period of phlebotomine activity between 6 to $11 \mathrm{pm}$, with the largest number captured between 6 to 8 pm, representing $46.6 \%$ (Figure 1). In Pearson's correlation analysis, considering the periods of 6 to $8 \mathrm{pm}, 9$ to $11 \mathrm{pm}$ and 12 to $2 \mathrm{am}$, it was observed that the three main species presented a negative correlation of captures on the internal walls in relation to the externalones, the species $N y$. intermedia had a moderate negative correlation, with $\mathrm{r}=-0.517$, whereas the species Pi. fischeri and $\mathrm{Mg}$. migonei had a very strong negative correlation, with $\mathrm{r}=-0.974$ and $\mathrm{r}=-0.953$, respectively.

\section{Captures with light traps in the first and second phase of study}

The representation of phlebotomines captured by light traps in three environments (household, peridomicileand forest), in the years 1994 to 1996, are shown in Figure 2, totaling 2,243 phlebotomines, and in 2015 to 2016, totaling 2,435 specimens. Most of them were captured in the peridomicile, $74.9 \%$ in the first phase and $52.6 \%$ in the second, followed by the households with $14.8 \%$ and $31.3 \%$, and the forest with $10.3 \%$ and $16.1 \%$, respectively. Only the three most numerous species were found in the traps
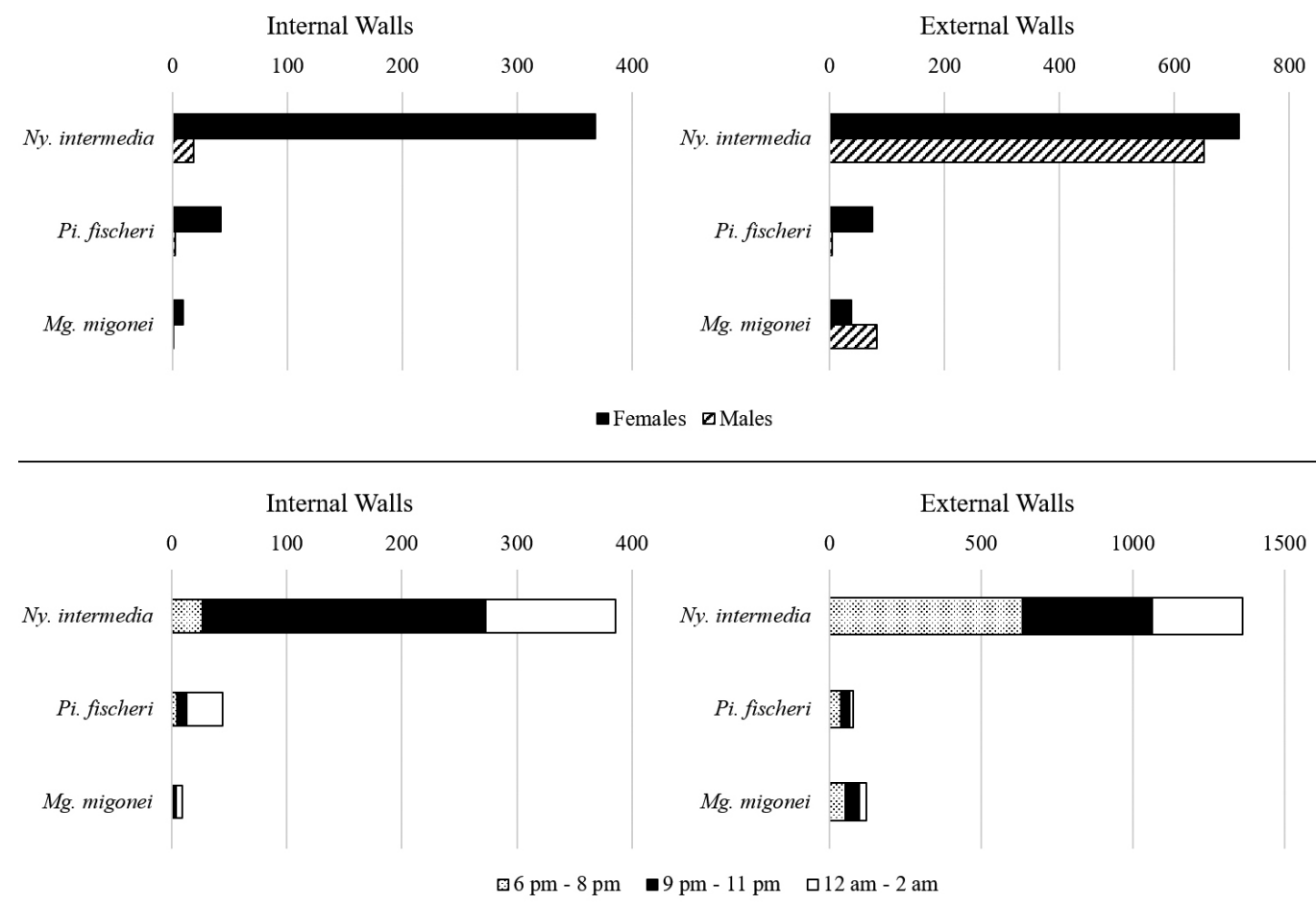

Figure 1 - Number of females and males and the hourly frequency of phlebotomines of the species Nyssomyia intermedia, Pintomyia fischeri and Migonemyia migonei, captured on the internal and external walls of the households, from October 1994 to September 1996, in the municipality of Mangaratiba, Rio de Janeiro State, Brazil. 
$1994-1996$
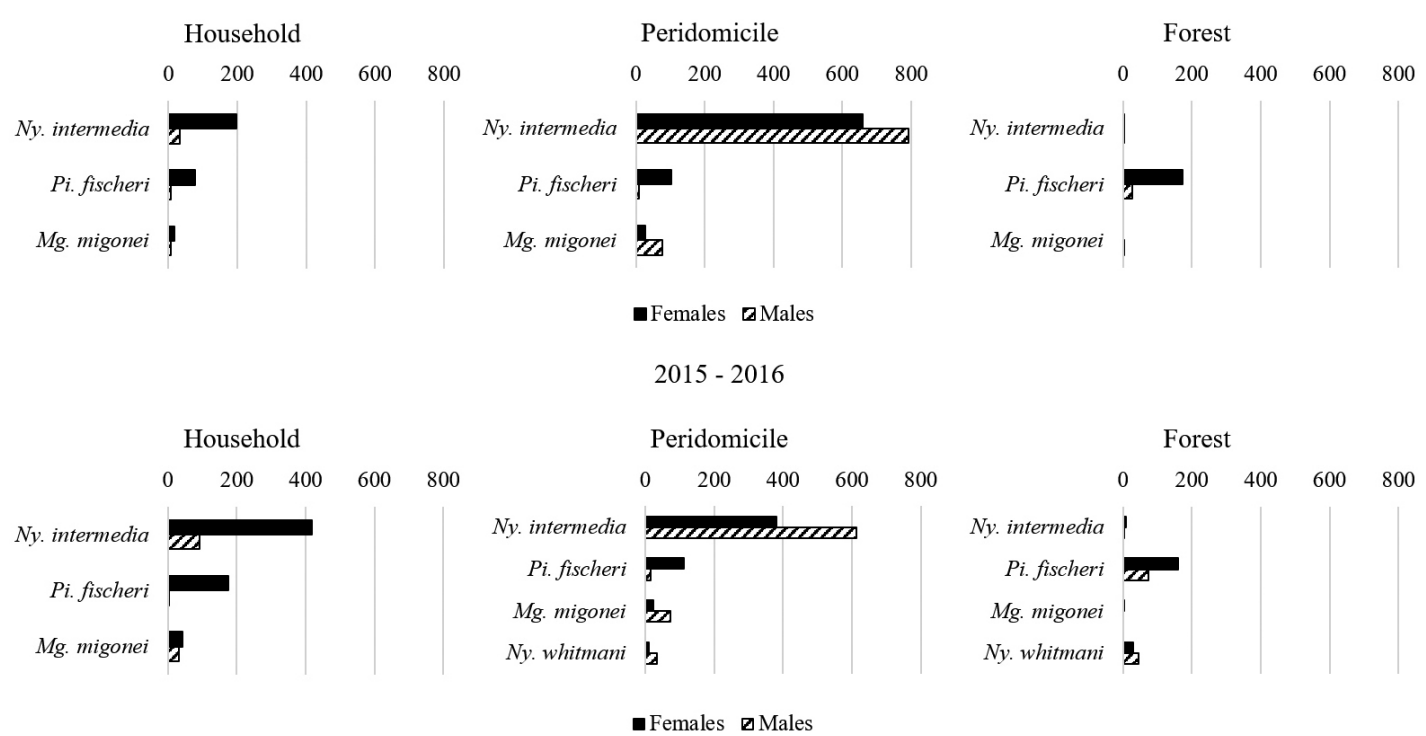

Figure 2 - Number of phlebotomines of the species Nyssomyia intermedia, Pintomyia fischeri, Migonemyia migonei and Ny. whitmani, captured by light traps, installed in the households, the peridomicile and in the forest, from October 1994 to September 1996 and October 2015 to September 2016, in the municipality of Mangaratiba, Rio de Janeiro State, Brazil.

installed inside the houses in the two phases of this study: Ny. intermedia, Pi. fischeri and Mg. migonei. Despite the increase in the percentage of specimens captured in the household in the second phase compared to the first phase, the three predominant species that are important vectors of Leishmania braziliensis had similar behaviors in the two phases. Ny. intermedia showed greater numbers than the other species and superiority in the peridomicile, followed by Pi. fischeri and Mg. migonei.

In the forest, the predominant species was Pi. fischeri, and it is important to note that $N y$. intermedia and Mg. migonei had insignificant numbers in this environment and in the second phase, among the least numerous species, Ny. whitmani stood out, and the same did not occur in the households, that showed a discreet presence in the peridomicile and greater numbers in the forest.

Regarding the sex, the number of females was higher than the number of males in the households, Ny. intermedia representing $86 \%$ of females in the first phase and $82.1 \%$ in the second phase, while Pi. fischeri showed the greatest disproportion, with $92.7 \%$ and $98.9 \%$, respectively. In the peridomicile, in relation to $N y$. intermedia and $M g$. migonei, the situation was reversed, with the number of males surpassing that of females, correponding to a percentage of $54.5 \%$ in the first phase and $61.6 \%$ in the second phase for the first species, $73.6 \%$ in the 90 's and $75.5 \% 20$ years later, for the second species. In contrast, Pi. fischeri maintained the disproportion between sexes in the peridomicile, with $92.8 \%$ and $88.1 \%$ of females, respectively. In the forest, the females of Pi. fischeri outweighted the males, in the proportion of $86.1 \%$ in the first phase and in a smaller proportion in the second phase, with $68.2 \%$, however, the number of male specimens increased significantly in relation to the other environments. In this environment, $N y$. whitmani was the second in order of frequency in the second phase, representing $19.1 \%$ of the total.

\section{Seasonality of the main species of the first and second phase of study}

The seasonality of epidemiological important species is shown in Figure 3, with Ny. intermedia, Pi. Fischeri and $M g$. migonei revealing all captured types in the first and second phases of the study. Similar behavior was observed in both phases during the hottest and most humid periods of the year (December, January and February), when the majority of the specimens of these species were captured (52.4\% in the first phase and $49.2 \%$ in the second phase). From October to March of the first phase, and September as well as November to March in the second phase showed $N y$. intermedia with a higher number of specimens captured than its XW of 199.6 in the first phase and 107.5 in the second phase of the study. The same was observed for $P i$. fischeri in the second phase in the months of September as well as November to March, in that the number of specimens captured was higher than the XW of 38.9 , and in the 1990s the XW of 39.0 was surpassed in the months of September to January and March. Migonemyia migonei had its absolute numbers above the XW of 17.2 in the months of September to February from 1994 to 1996 and 20 years later, 

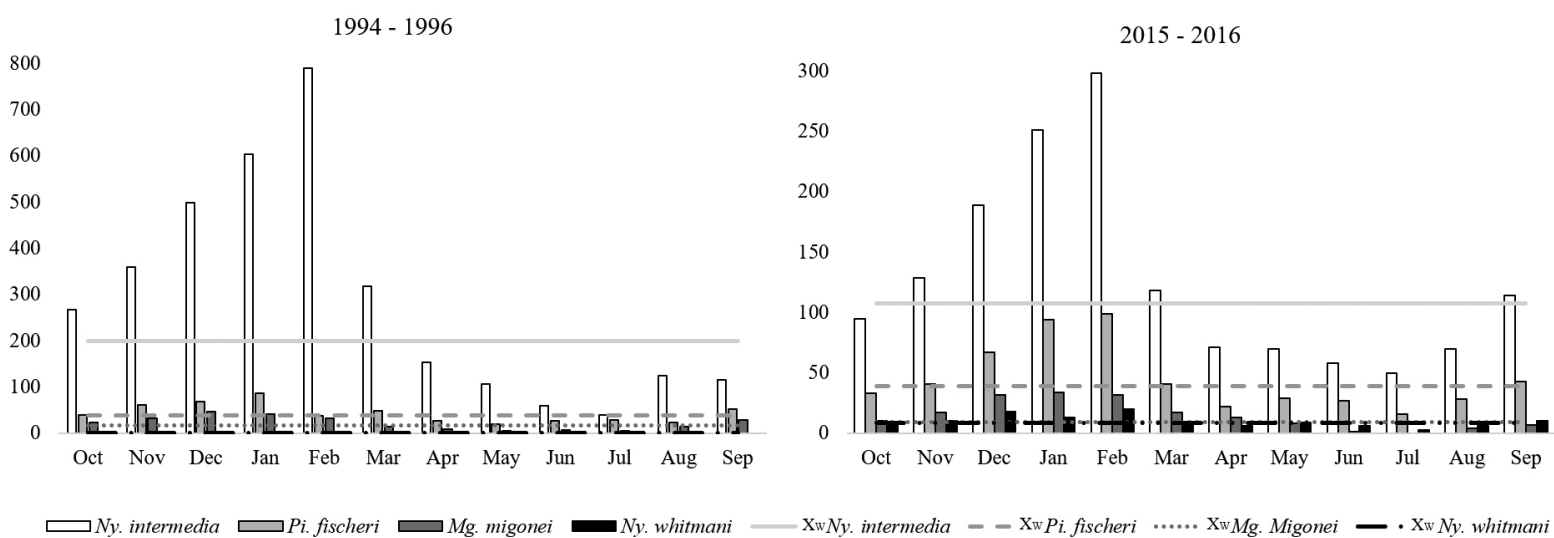

Figure 3 - Seasonality and the Williams' averages (XW) of phlebotomines of the species Nyssomyia intermedia, Pintomyia fischeri, Migonemyia migonei and Ny. whitmani, from October 1994 to September 1996 and October 2015 to September 2016, in the municipality of Mangaratiba, Rio de Janeiro State, Brazil.

from October to April presented an XW of 9.3. In contrast, there was a sharp decline in the capture of specimens in the coldest and driest quarter of the year (May through July), with the lowest number of $N y$. intermedia and $M g$. migonei in July of both periods, whereas Pi. fischeri had the least numbers in May in the first phase, and July in the second phase. Among the less frequent species, Ny. whitmani was present from January to June in the captures made in the mid-1990s, with XW of 0.6 and 20 years later, it was present in all months of the year, with the highest number in February and the lowest in July, during September to February and in May the number of specimens captured of this species was greater than its $\mathrm{XW}$ of 8.9.

\section{Abundance of the species of the second phase of study}

Regarding the abundance of species, in the second phase of the study, using light traps, and searching in the households, the peridomicile and the forest, it was found that $N y$. intermedia (household and peridomicile) was the most abundant species, followed by Pi. fischeri and Mg. migonei. Nyssomyia whitmani was the fourth most abundant species in the peridomicile ranking. In the forest, the most abundant species was Pi. fischeri, followed by $N y$. whitmani and Pi. bianchigalatiae. Adding the results found in the three collection sites, the household, the peridomicile and the forest, it was found that the most abundant species was Pi. fischeri, being the first in the ranking with SISA 0.897 , Ny. intermedia ranking second with SISA 0.722, Ny. whitmani ranking third with SISA 0.466 and $M g$. migonei in fourth position with 0.440 (Table 2).

\section{DISCUSSION}

From 2001 to 2019, 2,547 cases of ATL were recorded in Rio de Janeiro State, with the highest number in the Metropolitan region of the State (51\%), followed by the Costa Verde region with $20 \%$ of the cases and of these,

Table 2 - Total (T) phlebotomines, Abundance Index (SISA) and Final Classification (Rank), captured in the household, peridomicile and in the forest, from October 2015 to September 2016, in the Municipality of Mangaratiba, Rio de Janeiro State, Brazil.

\begin{tabular}{|c|c|c|c|c|c|c|c|c|c|c|c|c|}
\hline \multirow{3}{*}{ Species } & \multicolumn{12}{|c|}{$2015-2016$} \\
\hline & \multicolumn{3}{|c|}{ Household } & \multicolumn{3}{|c|}{ Peridomicile } & \multicolumn{3}{|c|}{ Forest } & \multicolumn{3}{|c|}{ Total } \\
\hline & $\mathrm{T}$ & SISA & Rank & $\mathrm{T}$ & SISA & Rank & $T$ & SISA & Rank & $\mathrm{T}$ & SISA & Rank \\
\hline Nyssomyia intermedia & 509 & 1.000 & 1 & 993 & 1.000 & 1 & 11 & 0.167 & 6 & 1,513 & 0.722 & 2 \\
\hline Pintomyia fischeri & 178 & 0.667 & 2 & 126 & 0.833 & 2 & 236 & 1.000 & 1 & 540 & 0.897 & 1 \\
\hline Migonemyia migonei & 75 & 0.278 & 3 & 98 & 0.583 & 3 & 2 & 0.135 & 8 & 175 & 0.440 & 4 \\
\hline Nyssomyia whitmani & - & - & - & 43 & 0.542 & 4 & 75 & 0.821 & 2 & 118 & 0.466 & 3 \\
\hline Pintomyia bianchigalatiae & - & - & - & 13 & 0.215 & 5 & 33 & 0.622 & 3 & 46 & 0.291 & 5 \\
\hline Pintomyia pessoai & - & - & - & 8 & 0.111 & 6 & 16 & 0.359 & 4 & 24 & 0.165 & 6 \\
\hline Pintomyia monticola & - & - & - & - & - & - & 6 & 0.167 & 6 & 6 & 0.056 & 8 \\
\hline Psathyromyia shannoni & - & - & - & - & - & - & 12 & 0.269 & 5 & 12 & 0.090 & 7 \\
\hline Psychodopygus ayrozai & - & - & - & - & - & - & 1 & 0.051 & 9 & 1 & 0.017 & 9 \\
\hline Total & 762 & - & - & 1,281 & - & - & 392 & - & - & 2,435 & - & - \\
\hline
\end{tabular}


$6 \%$ were recorded in children under 4 years old, still involving women, as well as dogs, raising the hypothesis that the transmission is occurring in the households and the peridomicile ${ }^{14}$. Such observation could be reinforced by environmental characteristics, which may have favored Leishmania infections, mainly due to the proximity of the households and places for domestic animals (chicken coop, pigsty, corral, kennel and other pens), in addition to remaining forests, where the disease can also occur in its natural enzootic cycle.

To assess the hourly frequency of the specimens, this study observed that there is a greater risk for the human population to acquire ATL in the period from 6 to $9 \mathrm{pm}$ in the peridomicile and between $9 \mathrm{pm}$ to $2 \mathrm{am}$ in the household. Other authors have also shown a greater activity of these dipterans in this period ${ }^{3,15}$.

The greatest number of specimens, in addition to the greatest diversity, was found in the first phase of the study carried out in the 90 's, certainly because the captures were performed for two consecutive years and using two methods of capture, the manual vacuum and the light trap. Of the species obtained, in both periods, six have already been registered in natural infections by protozoa of the genus Leishmania, $\mathrm{Ny}$. intermedia, Pi. fischeri, $\mathrm{Mg}$. migonei, $N y$. whitmani and Pi. pessoai by Leishmania (V.) braziliensis; and Ps. ayrozai by Leishmania (V.) naiff. The species $M g$. migonei was also found naturally infected by Leishmania infantum chagasi, in Northeastern Brazil ${ }^{16}$. Of the four predominant species in this study, $N y$. intermedia, $M g$. migonei and Ny. whitmani has a wide geographic distribution in Brazil, occurring in the five regions of the country, Pi. fischeri, in four Brazilian regions, Northeast, Midwest, Southeast and South, and not yet registered in the North ${ }^{17}$.

The same authors in several regions of Rio de Janeiro State observed the progressive association of $N y$. intermedia and $\mathrm{Mg}$. migonei to human households and the coincident distribution of the first species with the banana monoculture ${ }^{2,3,6,17-25}$. Regarding the second species, Rangel and Lainson ${ }^{24}$ suggested that it could have a secondary role in the transmission of the etiological agent of ATL, especially due to the presence of dogs which are strong attractants for blood feeding.

A noteworthy fact was the proof of the drastic reduction in the number of specimens of $\mathrm{Ny}$. intermedia inside the forest, in comparison with the household and the peridomiciliary environments, both in the first and second phases of the study. The low density of phlebotomines in the forest was also observed in other endemic areas of the State ${ }^{2,3}$, suggesting that the species is not important for the transmission of ATL in the wild, whereas in areas close to the environment modified by humans, it may be in the process of domiciliation.

In two Guarani indigenous villages, located in the Costa Verde region, in the municipality of Paraty, South coast of Rio de Janeiro State, Ny. intermedia was the most prevalent species in captures made in the two villages ${ }^{26}$. In the same year, Novo et al. ${ }^{27}$, on the Marambaia island, in the municipality of Mangaratiba, captured the species $N y$. intermedia and $\mathrm{Mg}$. migonei in greater densities.

In the present study, the number of $N y$. intermedia females captured by light traps in the households predominated in the second phase of the study, probably attracted to humans. In contrast, there was a higher proportion of males than females in the peridomiciliary environment. However, in all places where the species prevailed, the numbers revealed greater activity in the peridomiciliary/household environments, a fact that has also been observed in the municipality of Angra dos Reis, neighboring Mangaratiba ${ }^{3}$. In the captures made on the external walls of the households in the first phase of the study, copulating specimens of $N y$. intermedia were recorded and confirmed by laboratory assemblage and identification. There is generally a balance between the sexes or a greater number of males, and because they seek copulation a few hours after emerging, it can be suggested that the breeding sites and natural shelters of the species are close to the human environment and associated with the banana culture, corroborating the results reported in the literature ${ }^{2,3,22}$. The reduced number of species in the forest in the two phases of the study suggests its ability to adapt to the anthropic environment. Its anthropophilia was observed in this study by a significant number of specimens biting the team when they were carrying out the manual captures; this behavior has been confirmed by other authors ${ }^{28}$. The high prevalence observed in this and other studies conducted close to the region ${ }^{26}$ indicates that this species acts as the main vector of Leishmania (V.) braziliensis in the areas of ATL occurrence in Costa Verde, in the municipality of Mangaratiba.

The presence of Pi. fischeri in the households and the peridomicile, represented by a higher number of females, suggests that the species is not yet in the process of domiciliation, maintaining its breeding grounds and natural shelters in the forest. It can be said, however, that the species showed a high degree of eclecticism, since a significant number of females was found in the three collection sites, the household, the peridomicile and the forest, probably attracted to exercise hematophagy. Considering also that there was a significant number of specimens in all the places of capture and observing the distances from the households to the forest, of approximately 300 meters, the data suggest 
that this species is of greater dispersion in the study area. In addition to the important epidemiological factors, proving their high anthropophilia, degree of eclecticism and endophilia, combined with the always significant occurrence of in ATL outbreaks in the Southeast region, the results suggest that this species acts, together with Ny. intermedia, as a vector of Leishmania (V.) braziliensis in the household/ peridomiciliary environments and, since it still maintains a predominant population in the forest, it can also participate in the transmission in its natural enzootic cycle. The species was the most abundant, in the second phase of the study. The importance of Pi. fischeri becomes more evident, in an urban area of the city of Porto Alegre, Rio Grande do Sul State, as it was found naturally infected with Leishmania $(V$.$) braziliensis, in areas with reported$ human cases ${ }^{29}$.

Other authors have also indicated Pi. fischeri, in Sao Paulo State, in the municipality of Botucatu, as a possible vector for Leishmania (V.) braziliensis in the area $^{30}$. Also in Serra da Cantareira, in the greater Sao Paulo region, the species appeared as a possible vector, due to its predominance and anthropophilia ${ }^{31}$.

Studies carried out on ATL in Ilha Grande, Rio de Janeiro State, revealed the migration of $M g$. migonei to households where human cases of the disease were subsequently identified, and it was suggested that the role of vector was shared with $N y$. intermedia ${ }^{32,33}$. However, on Ilha Grande, as in other endemic areas of Rio de Janeiro State, analyses of the feeding preferences of phlebotomines demonstrated that, although practicing anthropophilia, they are strongly attracted to dogs for blood feeding, indicating that this phlebotomine could be participating in the maintenance of canine leishmaniasis ${ }^{2,3,19,23,34,35}$. In Pernambuco State, reports of $M g$. migonei infected by Leishmania infantum chagasi, the etiological agent of American visceral leishmaniasis, suggest that this species may serve as the vector for this pathogen in areas where Lu. longipalpis and $L u$. cruzi are absent ${ }^{16}$.

In this study, Mg. migonei ranked fourth among the most abundant species. Although there was no research on shelters and natural breeding sites, the results indicated that there is a possibility that their habitat is close to the households, especially near the places of domestic animals, where the species is abundant, and with a greater number of males than females. Mg. migonei may be the species with the highest level of domiciliation, and a great potential to find humans, particularly due to the adaptation to the anthropized environment and its proven affinity for feeding on the blood of dogs. Therefore Mg. migonei may be an adjunct in the transmission of Leishmania (V.) braziliensis in the studied areas.
In studies performed in Rio de Janeiro State in areas of transmission of the etiologic agent of ATL, Ny. intermedia and $N y$. whitmani could be captured in the peridomicile, where they were found blood-feeding, and in the nearest forest. In the peridomicile, the former predominated, while in the forest, the latter prevailed $d^{2,3,23,24,35}$. In addition to this epidemiological evidence, the discovery of natural infections by Leishmania (V.) braziliensis and Leishmania (V.) shawi has indicated the participation of $N y$. whitmani in the transmission of ATL etiological agents ${ }^{35}$. Rangel et al. ${ }^{21}$ observed morphometric, biological and molecular differences in this species and suggested that $N y$. whitmani could be a actually a complex of cryptic species or a species with a high capacity of adaptation to changing environments. According to Costa et $a l .^{36}$, the species has been registered in several types of vegetation, such as the Amazon Forest, representative areas of "dense rain-forest," "open rain-forest," and "mixed rain-forest," the Savanna, Campos Cerrados, Northeastern Caatingas, or Savana Estepica and the Atlantic Primary Forest. Investigations carried out in the Serra de Baturite in Ceara State found this species naturally infected by flagellates that were identified through DNA analysis as belonging to the genus Leishmania of the subgenus Viannia ${ }^{37}$. New infections were subsequently found, and the characterization of the parasites after isolation identified them as Leishmania (V.) braziliensis $^{38}$. Nyssomyia whitmani has been observed as the vector of ATL in several locations in Brazil. Brazil et al. ${ }^{18}$ showed geographical differences in feeding activities, raising the suspicion that this is actually a species complex. According to those authors, Ny. whitmani no longer has a wild characteristic in Northeastern Brazil, undergoing adaptations according to the new environments modified by humans, making it the most anthropophilic and dominant species in this region of the country.

The species Ny. whitmani, 20 years after the first collection, even with a much smaller number of specimens, had a significant presence, ranking third according to the abundance index, above all by the relatively expressive number in the forest, but still with a marked presence in the household environment. In areas of active foci of ATL on the coastline of Rio de Janeiro State, the species has emerged with the potential for a gradual adaptation to environments modified by anthropic action in the Costa Verde region ${ }^{2}$. Because it is considered an important vector in other regions of Brazil, the greater number of specimens captured in the human environment, indicates that the species can also become an important vector in the region, along with $N y$. intermedia, Pi. fischeri and Mg. migonei.

The period of greatest density of phlebotomines was in the warmest months of the year, where high temperatures, 
high relative humidity and typical summer rainfall were observed. In the colder months, the fauna suffered a decline; however, the species that proved to be vectors of ATL, Ny. intermedia, Pi. fischeri, Mg. migonei and Ny. whitmani were captured throughout the year. A study carried out in an area of the Atlantic Forest in the Northeast region of Brazil under anthropic pressure, observed a seasonal behavior for most sand flies species captured, and changes in their composition and population dynamics associated with local adaptations ${ }^{39}$.

The municipality of Mangaratiba endured great environmental impacts beginning in the 1970s, mainly due to the construction of the Rio-Santos highway and the renewal of its municipal port (which was lost after construction of the Dom Pedro II Railway in the $19^{\text {th }}$ century, connecting the cities of Rio de Janeiro and Sao Paulo). This led to the inauguration of the Guaiba Island iron ore terminal, causing a great demographic expansion in the region, leading to a larger and real development linked to the construction of condominiums, resorts and luxury hotels, which stimulated the local economy. The Port of Sepetiba, the current Port of Itaguai, and the event of the Metropolitan Arch have also contributed to the increase in the floating population of the region with the expansion of the beach tourism ${ }^{5}$. During the 20 years of study in the region, despite the increasing action of humans, there has been no change in the profile of the phlebotomine fauna, especially in relation to the most frequent species, such as Ny. intermedia, Pi. fischeri and Mg. migonei. However, a higher density of these species with medical and veterinary importance was observed in the second phase of the study in the areas of environmental impact, where a larger number of specimens was obtained than in the first phase conducted over two years using light traps. A high number of specimens of these main species were found in the household environment, likely caused by their greater adaptation to the anthropic environment, mainly peridomiciliar, since in this environment the number of males captured was significantly greater than females. This increase was also observed among the less numerous species, such as $N y$. whitmani, one of the most important ATL vector species in Brazil ${ }^{23}$, which reinforces the importance of entomological and epidemiological surveillance in the area.

\section{ACKNOWLEDGMENTS}

This study was financed in part by the Coordenação de Aperfeiçoamento de Pessoal de Nível Superior - Brasil (CAPES) - Finance Code 001.

\section{REFERENCES}

1. Brasil. Ministério da Saúde. Secretaria de Vigilância em Saúde. Departamento de Vigilância das Doenças Transmissíveis. Manual de vigilância da leishmaniose tegumentar. Brasília: Ministério da Saúde; 2017. [cited 2021 Jul 15]. Available from: http://bvsms.saude.gov.br/bvs/publicacoes/manual_vigilancia_ leishmaniose_tegumentar.pdf

2. Vieira VR, Azevedo AC, Alves JR, Guimarães AE, Aguiar GM. Ecological aspects of Phlebotomine sand flies (Diptera, Psychodidae, Phlebotominae) in areas of American cutaneous leishmaniasis, in the municipality of Paraty, Rio de Janeiro, Brazil: I-Index of abundance by location and type of capture. J Med Entomol. 2015;52:886-95.

3. Aguiar GM, Azevedo AC, Medeiros WM, Alves JR, Rendeiro V. Aspects of the ecology of Phlebotomines (Diptera: Psychodidae: Phlebotominae) in an area of cutaneous leishmaniasis occurrence, municipality of Angra dos Reis, coast of Rio de Janeiro State, Brazil. Rev Inst Med Trop Sao Paulo, 2014;56:143-9.

4. Rio de Janeiro. Instituto Estadual do Ambiente. Biodiversidade e território: conheça as unidades de conservação. [cited $2021 \mathrm{Jul}$ 15]. Available from: http://www.inea.rj.gov.br/biodiversidadeterritorio/conheca-as-unidades-de-conservacao/

5. Bondim M. Mangaratiba: história. [cited 2021 Jul 15]. Available from: https://www.mangaratiba.rj.gov.br/novoportal/pagina/ historia.html

6. Aguiar GM, Medeiros WM, De Marco TS, Santos SC, Gambardella S. Ecologia dos flebotomíneos da Serra do Mar, Itaguaí, Estado do Rio de Janeiro, Brasil: I - A fauna flebotomínica e prevalência pelo local e tipo de captura (Diptera, Psychodidae, Phlebotominae). Cad Saude Publica. 1996;12:195-206.

7. Pugedo H, Barata RA, França-Silva JC, Silva JC, Dias E. HP: um modelo aprimorado de armadilha luminosa de sucção para captura de pequenos insetos. Rev Soc Bras Med Trop. 2005;38:70-2.

8. Young DG, Perkins PV. Phlebotominae sand flies of North America (Diptera: Psychodidae). Mosq News. 1984;44:263304.

9. Galati EA. Phlebotominae (Diptera, Psychodidae): classification, morphology and terminology of adults and identification of American taxa. In: Rangel EF, Shaw JJ, editors. Brazilian sand flies: biology, taxonomy, medical importance and control. Cham: Springer International Publishing; 2018. p.9-212.

10. Roberts DR, Hsi BP. An index of species abundance for use with mosquito surveillance data. Environ Entomol. 1979;8:1007-13.

11. Haddow AJ. Studies of the biting habits of African mosquitoes: an appraisal of methods employed, with special reference to the twenty-four-hour catch. Bull Entomol Res. 1954;45:199242. 
12. Haddow AJ. Studies on the biting habits and medical importance of East African mosquitos in the Genus Aedes: I. Subgenera Aedimorphus, Banksinella and Dunnius. Bull Entomol Res. 1960;50:759-79.

13. Forattini OP, Gomes AC, Santos JL, Galati EA, Rabello EX, Natal D. Observações sobre atividade de mosquitos Culicidae, em mata residual do Vale do Ribeira, S. Paulo, Brasil. Rev Saude Publica. 1981;15:557-86.

14. Brasil. Sistema de Informação de Agravos de Notificação. Dados epidemiológicos Sinan. [cited 2021 Jul 15]. Available from: https://portalsinan.saude.gov.br/dados-epidemiologicos-sinan

15. Moutinho FF, Souza MB, Carvalho RW. Flebotominos de las zonas endémicas de leishmaniasis cutánea americana en Paraty, Rio de Janeiro, Brasil. Rev Colomb Entomol. 2010;36:82-5.

16. Carvalho RM, Valença HF, Silva FJ, Pita-Pereira D, Pereira TA, Britto C, et al. Natural Leishmania infantum in Migonemyia migonei (França, 1920) (Diptera: Psychodidae: Phlebotominae) the putative vector of visceral leishmaniasis in Pernambuco State, Brazil. Acta Trop. 2010;116:108-10.

17. Aguiar GM, Vieira VR. Regional distribution and habitats of Brazilian Phlebotomine species. In: Rangel EF, Shaw JJ, editors. Brazilian sand flies: biology, taxonomy, medical importance and control. Cham: Springer International Publishing; 2018. p.251-98.

18. Brazil RP, Almeida DC, Brazil BG, Mamede SM. Chicken house as a resting site of sandflies in Rio de Janeiro, Brazil. Parassitologia. 1991;33 Suppl:113-7.

19. Aguiar GM, Medeiros WM, Santos TG, Klein AF, Ferreira VA. Ecology of sandflies in a recent focus of Cutaneous Leishmaniasis in Paraty, litoral of Rio de Janeiro State (Diptera, Psychodidae, Phlebotominae). Mem Inst Oswaldo Cruz. 1993;88:339-340.

20. Carvalho RW, Serra-Freire NM, Souza MB. Fauna de flebótomos da Ilha do Araújo, Município de Paraty - RJ: 1 - Diversidades e aspectos do comportamento. Parasitol Dia. 1995;19:104-12.

21. Rangel EF, Lainson R, Souza AA, Ready P, Azevedo AC. Variation between geographical populations of Lutzomyia (Nyssomyia) whitmani (Antunes and Coutinho, 1939) Sensu Lato (Diptera: Psychodidae: Phlebotominae) in Brazil. Mem Inst Oswaldo Cruz. 1996;91:43-50.

22. Rangel EF, Meneses C, Azevedo A, Franco A, Moreira C, Mayrink A, et al. Leishmaniose cutânea no Estado do Rio de Janeiro, Brasil: ciclo silvestre e o elo de ligação com o peridomicílio. Rev Soc Bras Med Trop. 1998;31 Suppl 1:132.

23. Rangel EF, Lainson R, Carvalho BM, Costa SM, Shaw JJ. Sand fly vectors of American cutaneous leishmaniasis in Brazil. In: Rangel EF, Shaw JJ, editors. Brazilian sand flies: biology, taxonomy, medical importance and control. Cham: Springer International Publishing; 2018. p.341-80.

24. Rangel EF, Lainson R. Proven and putative vectors of American cutaneous leishmaniasis in Brazil: aspects of their biology and vectorial competence. Mem Inst Oswaldo Cruz. 2009;104:93754

25. Rangel EF, Barbosa AF, Andrade CA, Sousa NA, Wermelinger ED. Development of Leishmania (Viannia) braziliensis (Vianna, 1911) in Lutzomyia intermedia (Lutz \& Neiva, 1912) (Diptera: Psychodidae: Phlebotominae) under experimental conditions. Mem Inst Oswaldo Cruz 1992;87:235-8

26. Barbosa GM, Marzochi MC, Carvalho RW, Alonso RS, Novo SP, Souza MB. Fauna flebotomínica em duas aldeias indígenas Guarani do município de Parati, Rio de Janeiro, Brasil. Rev Cien Tec UNIG. 2013;13:54-62.

27. Novo SP, Souza MB, Villanova CB, Meródio JC, Meira AM. Survey of sandfly vectors of leishmaniasis in Marambaia Island, municipality of Mangaratiba, State of Rio de Janeiro, Brazil. Rev Soc Bras Med Trop. 2013;46:231-3.

28. Afonso MM, Gomes AC, Meneses CR, Rangel EF. Studies on the feeding habits of Lutzomyia (N.) intermedia (Diptera, Psychodidae), vector of cutaneous leishmaniasis in Brazil. Cad Saude Publica. 2005;21:1816-20.

29. Pita-Pereira D, Souza GD, Pereira TA, Zwetsch A, Britto C, Rangel EF. Lutzomyia (Pintomyia) fischeri (Diptera: Psychodidae: Phlebotominae), a probable vector of American cutaneous leishmaniasis: detection of natural infection by Leishmania (Viannia) DNA in specimens from the municipality of Porto Alegre (RS), Brazil, using multiplex PCR assay. Acta Trop. 2011;120:273-5.

30. Cutolo AA, Galati EA, Von Zuben CJ. Sandflies (Diptera, Psychodidae) from forest areas in Botucatu municipality, central western São Paulo State, Brazil. J Venom Anim Toxins Incl Trop Dis. 2013;19:15.

31. Moschin JC, Ovallos FG, Sei IA, Galati EA. Ecological aspects of phlebotomine fauna (Diptera, Psychodidae) of Serra da Cantareira, Greater São Paulo Metropolitan region, state of São Paulo, Brazil. Rev Bras Epidemiol. 2013;16:190-201.

32. Araújo Filho NA, Sherlock IA, Coura JR. Leishmaniose tegumentar americana na Ilha Grande, Rio de Janeiro: VI. Observações sobre a frequência horária e variação mensal dos transmissores. Rev Soc Bras Med Trop. 1981;14:185-95.

33. Carvalho BM, Maximo M, Costa WA, Santana AL, Costa SM, Rego TA, et al. Leishmaniasis transmission in an ecotourism area: potential vectors in Ilha Grande, Rio de Janeiro State, Brazil. Parasit Vectors. 2013;6:325.

34. Rangel EF, Souza NA, Wermelinger ED, Azevedo AC, Barbosa AF, Andrade CA. Flebótomos de Vargem Grande, foco de leishmaniose tegumentar no Estado do Rio de Janeiro. Mem Inst Oswaldo Cruz. 1986;81:347-9.

35. Souza NA, Andrade-Coelho CA, Peixoto AA, Rangel EF. Nocturnal activity rhythms of Lutzomyia intermedia and Lutzomyia whitmani (Diptera: Psychodidae) in a transmission area of American cutaneous leishmaniasis in Rio de Janeiro State, Brazil. J Med Entomol. 2005;42:986-92. 
36. Costa SM, Cechinel M, Bandeira V, Zannuncio JC, Lainson R, Rangel EF. Lutzomyia (Nyssomyia) whitmani s.l. (Antunes and Coutinho, 1939) (Diptera: Psychodidae: Phlebotominae) geographical distribution and the epidemiology of American cutaneous leishmaniasis in Brazil: mini-review. Mem Inst Oswaldo Cruz. 2007;102:149-53.

37. Azevedo AC, Rangel EF, Costa EM, David J, Vasconcelos AW, Lopes UG. Natural infection of Lutzomyia (Nysomyia) whitmani (Antunes and Coutinho, 1939) by Leishmania of the braziliensis complex in Baturité, Ceará State, Northeast Brazil. Mem Inst Oswaldo Cruz. 1990;85:251.
38. Queiroz RG, Vasconcelos IA, Vasconcelos AW, Pessoa FA, Souza RN, David JR. Cutaneous leishmaniasis in Ceará State in Northeast Brazil: incrimination of Lutzomyia whitmani (Diptera: Psychodidae) as a vector of Leishmania braziliensis in Baturité municipality. Am J Trop Med Hyg. 1994;50:693-8.

39. Pinheiro MP, Silva-Inacio CL, Silva MM, Araújo PS, Ximenes MF. Potential vectors of Leishmania spp. in an Atlantic Forest conservation unit in Northeastern Brazil under anthropic pressure. Parasit Vectors. 2021;14:38. 